\title{
Global neurosurgery: the role of the individual neurosurgeon, the Foundation for International Education in Neurological Surgery, and "service through education" to address worldwide need
}

\author{
Robert J. Dempsey, MD \\ Department of Neurological Surgery, University of Wisconsin SMPH, Madison, Wisconsin
}

$\mathrm{W}$ ORLDWIDE understanding of the importance of neurosurgical care in the developing world has dramatically changed in the past few years. Heightened interest in the importance of basic surgical needs has changed decades of emphasis from primarily infectious disease. The Lancet Commission and the World Bank recently emphasized essential surgical care as a basic necessity for humankind. They state that between 5 and 6 billion people worldwide lack this care. ${ }^{6}$ As many as 22 million people per year may require the expertise of a neurosurgeon, and yet approximately 5 million essential neurosurgical cases per year are not addressed in low- and middle-income countries. ${ }^{4}$ Worldwide preventable deaths from the entire surgical deficit may be as many as 47 million annually. ${ }^{6}$ The 2015 World Bank document estimates trillions of dollars of economic cost, as well as the moral certainty that the world must work together in humanitarian efforts to address this need.,10 Subsequently, the World Health Organization (WHO) resolved unanimously to endorse a decree to address this concern by all member ministers of health.

There are multiple methods to address such a need. The article by Rosseau et al. shows the key relationship of the WHO and organizations such as the World Federation of Neurosurgical Societies (WFNS). ${ }^{9}$ All such efforts, however, must start with an understanding of the role of individual neurosurgeons and the concept of "service through education"3 expressed by the Foundation for International Education in Neurological Surgery (FIENS).

The role of neurosurgery in addressing an essential surgical shortfall is key. One cannot establish a successful trauma system without neurosurgical care. It is well understood that head and spine trauma are a primary cause of mortality in modern trauma. Complete care in multiple areas of medicine is not possible without neurosurgical care. Maternal and child care does not allow one to deal with congenital defects of the CNS without neurosurgical input. Benign tumors, cranial vascular events, and abscesses are all treatable conditions, which with neurosurgical care can return millions of young people to productive lives-yet without access to neurosurgical care these are not treatable. It is their lost contribution to the developing economy and the substantial drain on their families, who will often leave their farm or job to journey great distances in an unsuccessful attempt to obtain care for their loved one, which results in the human and economic cost. ${ }^{11}$ As society changes and life expectancy increases even in the developing world, the character of the diseases will change as well. Stroke will take on a major role and is predicted to become the number one cause of death and disability in the developing world in the next decade, surpassing infection. Neurosurgery needs to play a vital role in combating this disease, both hemorrhagic and ischemic stroke, as well as the still relatively unaddressed problems of spinal disorders and pain in the developing world. Without addressing these shortfalls, the economy and its medical system cannot develop?

Since 1969, FIENS has used its experience to work with individual neurosurgeons to develop sustainable surgical programs of education within the countries in need rather than providing episodic service alone. Although episodic service helps individuals who are served, it does not have a lasting or self-sustaining impact beyond the time of the volunteer. The goal of service through education is to supply infrastructure, local support, equipment, and certification and education programs, which establishes the 
neurosurgeon's practice. It trains neurosurgeons in their country or region of need. It moves a health system in the developing country toward being self-sustaining. The efforts of FIENS are based on partnering with the WHO and major worldwide societies to help find a role for individual neurosurgeons to participate in answer to their humanitarian desires, which led them into the field in the first place. FIENS works to identify local leaders to champion programs at training sites, often through personal contacts. It then partners with major educational societies, from the WHO to the WFNS to the Society of Neurological Surgeons (SNS), etc. In 2016 it developed, along with the SNS, an international curriculum capable of establishing a standard of training that would be recognizable to local certifying groups. Further educational objectives have been advanced by establishing international dyads linking established training programs throughout the world with new training programs in the developing world. With decades of experience in this effort, the dyads have been used for an exchange of teachers and trainees to help identify infrastructure and equipment needs, and to work to supply them. Such relationships have been invaluable in assuring the recognition and certification of the new training program within their own country or region.

Graduates of such programs in the developing world must be supported. They must have equipment, colleagues, and infrastructure, or they cannot practice in their home country and will migrate to established regions of the world. FIENS works to support the graduates so they can establish their own program within the developing world. This includes major educational offerings, which require the partnerships of a wide variety of organizations, from governmental to academic to philanthropic. ${ }^{11}$ These partnerships have worked together to establish not only curriculum and milestone standards recognizable to US neurosurgeons, but also the concept of combined educational offerings (or "boot camps"), which were originated in the US by the SNS, and successfully established in South America (2015), Africa (2016), and Asia (2017)., ${ }^{1,5,8}$ The remarkable impact of such partnerships allow the individual neurosurgeon, through his or her member societies, to have an impact on neurosurgical need locally and internationally. ${ }^{2}$ FIENS has also identified a program for exchange of educational opportunities, allowing selected graduates of the new programs to travel to their dyad partner site for 3-month periods of work in simulation laboratories, observerships, and educational opportunities to enhance the educational quality of the program in the developing country and complete training of the graduates.

The goals of such a program are ambitious, but by creating international partnerships, infrastructure may be built around such a curriculum of training. ${ }^{5}$ The American College of Surgeons (ACS) is now collaborating, building a multispecialty training site in Ethiopia based on this and other models of training. The WFNS has established multiple training centers in key sites of established neurosurgery centers in Africa, allowing trainees to work first in the host countries to learn their neurosurgical skills there by following an established curriculum, and then be supported by member societies, including FIENS volunteers, when they return to their country of origin. Establishing dyads with those new sites allows an understanding of equipment needs, biomedical help, and ongoing education. FIENS is working on modernizing communication, taking advantage of a revolution in Wi-Fi availability to allow real-time conferencing, patient discussions across the world, and even intraoperative consultation through merged screen visual communication of intraoperative endoscopies and microscopes. As such new programs develop, the specialized training, fundamental skills courses, and live surgery demonstrations become increasing sited at the new training centers, enhancing their educational offerings and credibility within their region. ${ }^{5}$ This then becomes a site for focused use of equipment, regional certification, and international education renewal. It also allows partnership across a wide range of organizations, while still involving the individual neurosurgeon.

The ongoing goals must be to both establish and maintain the continuity of programs of training. Only by training people in their region of need do we understand the infrastructure challenges that must be addressed to allow these specialists to remain in the area of need and develop self-sustaining programs. This is the only way that neurosurgery can address the critical shortfall of access to essential surgery in the developing world. By placing volunteers from established programs within dyads, opportunities abound for participants to safely and effectively achieve humanitarian goals. As electronic communication brings our world together, it is the international work of these key organizations that allows the individual neurosurgeon to have a profound impact on what was previously thought to be a daunting need.

Much has already been accomplished. In the past 20 years, sub-Saharan Africa has increased its distribution of 1 neurosurgeon to 8 million people to now approximately 1 per 2.4 million. More than 100 neurosurgeons are in various stages of training at this point in this geographic area of need, and FIENS programs are now training the trainers, with the result being that members of the newest group of residents identify with their national program, the very definition of a self-sustaining system of care. Humanitarian efforts are the very basis of neurosurgery. We, as individuals working together, can impact the disorders of trauma, benign tumors, congenital defects, pain, stroke, and cancer in ways not seen in other specialties. We therefore need to continue to foster a concept of service through education to allow our worldwide colleagues to take control of their neurosurgical need, with our partnering organizations such as FIENS truly becoming partners to our colleagues' leadership in their own countries.

https://thejns.org/doi/abs/10.3171/2018.7.FOCUS18363

\section{References}

1. Dempsey KE, Qureshi MM, Ondoma SM, Dempsey RJ: Effect of geopolitical forces on neurosurgical training in Sub-Saharan Africa. World Neurosurg 101:196-202, 2017

2. Dempsey RJ: Art, passion and neurosurgery: presidential address from the Society of Neurological Surgeons. World Neurosurg 76:378-384, 2011

3. Dempsey RJ, Nakaji P: Foundation for International Education in Neurological Surgery (FIENS) Global Health and Neurosurgical Volunteerism. Neurosurgery 73:10701071,2013 
4. Dewan MC, Rattani A, Fieggen G, Arraez MA, Servadei F, Boop FA, et al: Global neurosurgery: the current capacity and deficit in the provision of essential neurosurgical care. Executive Summary of the Global Neurosurgery Initiative at the Program in Global Surgery and Social Change. J Neurosurg [epub ahead of print April 27, 2018. DOI: 10.3171/2017.11.JNS171500]

5. Kahamba J, Assey A, Dempsey RJ, Qureshi M, Hartl R: The second African Federation of Neurological Surgeons course in the East, Central, and Southern Africa Region held in Dar es Salaam, Tanzania, January 2011. World Neurosurg 80:255-259, 2010

6. Meara JG, Hagander L, Leather AJM: Surgery and global health: a Lancet Commission. Lancet 383:12-13, 2014

7. Ng-Kamstra JS, Greenberg SLM, Abdullah F, Amado V, Anderson GA, Cossa M, et al: Global Surgery 2030: A roadmap for high income country actors. BMJ Glob Health 1:e000011, 2016

8. Park KB, Johnson WD, Dempsey RJ: Global neurosurgery: the unmet need. World Neurosurg 88:32-35, 2016

9. Rosseau G, Johnson WD, Park KB, Arráez Sánchez M, Servadei F, Vaughan KA: Global neurosurgery: current and potential impact of neurosurgeons at the World Health Organization and the World Health Assembly. Executive summary of the World Federation of Neurosurgical Societies-World Health Organization Liaison Committee at the 71st World Health Assembly. Neurosurg Focus 45(4):E18, 2018
10. Servadei F, Rossini Z, Nicolosi F, Morselli C, Park KB: The role of neurosurgery in countries with limited facilities: facts and challenges. World Neurosurg 112:315-321, 2018

11. United Nations: Millennium Development Goal 8. Taking stock of the global partnership for development. MDG Gap Task Force Report 2015. UN.org. (http://www.un.org/ millenniumgoals/pdf/MDG_Gap_2015_E_web.pdf) [Accessed August 14, 2018]

\section{Disclosures}

The author reports no conflict of interest.

\section{Correspondence}

Robert J. Dempsey: dempsey@neurosurgery.wisc.edu.

\section{INCLUDE WHEN CITING}

DOI: 10.3171/2018.7.FOCUS18363 